\title{
Psychological, social and health behaviour risk factors for deaths certified as asthma: a national case-control study
}

\author{
P M Sturdy, C R Victor, H R Anderson, J M Bland, B K Butland, B D W Harrison, \\ C Peckitt, J C Taylor, on behalf of the Mortality and Severe Morbidity Working Group \\ of the National Asthma Task Force
}

Thorax 2002;57:1034-1039

See end of article for authors' affiliations

\section{Correspondence to:} Professor H R Anderson, Department of Public Health Sciences, St.

George's Hospital Medical School, London SW17 ORE, UK;

r.anderson@sghms.ac.uk

Revised version received 22 July 2002

Accepted for publication

2 August 2002

Background: Uncontrolled studies suggest that psychosocial factors and health behaviour may be important in asthma death.

Methods: A community based case-control study of 533 cases, comprising $78 \%$ of all asthma deaths under age 65 years and 533 hospital controls individually matched for age, district and asthma admission date corresponding to date of death was undertaken in seven regions of Britain (1994-98). Data were extracted blind from anonymised copies of primary care records for the previous 5 years and non-blind for the earlier period.

Results: $60 \%$ of cases and $63 \%$ of controls were female. The median age in both groups was 53 . Cases had an earlier age of asthma onset, more chronic obstructive lung disease, and were more obese. $48 \%$ of cases and $42 \%$ of controls had a health behaviour problem; repeated non-attendance/ poor inhaler technique was related to increased risk of death. Overall, $85 \%$ and $86 \%$, respectively, had a psychosocial problem. Four psychosocial factors were associated with increased risk of death (psychosis, alcohol/drug abuse, financial/employment problems, learning difficulties) and two with reduced risk (anxiety/prescription of antidepressant drugs and sexual problems). While alcohol/drug abuse lost significance after adjustment for psychosis, other associations appeared independent of each other and of indicators of severity and co-morbidity. None of the remaining 13 factors including family problems, domestic abuse, bereavement, and social isolation were significantly related to risk of asthma death.

Conclusion: There was an apparently high burden of psychosocial problems in both cases and controls. The associations between health behaviour, psychosocial factors, and asthma death are varied and complex with a limited number of factors showing positive relationships.

$\mathrm{D}$ eath from asthma in Britain in those aged under 65 has halved from 2.09 per $10^{5}$ in 1986 to 1.02 per $10^{5}$ in 1999. ${ }^{12}$ Nevertheless, recent confidential enquiries still suggest that many of these premature deaths may be preventable. ${ }^{3-8}$ Previous case-control studies and audits of asthma deaths have suggested that risk factors fall into four main categories: (1) severity of the disease; (2) medical care factors (both in terms of the nature of the health care system and the management of the mortal event) ${ }^{3568-12}$; (3) health behaviour (adherence to management) ${ }^{3-81012}$; and (4) adverse psychosocial factors. . $^{3-6} 81013$

If psychosocial and health behaviour factors are important, this may offer opportunities for prevention, particularly as medical management continues to improve. ${ }^{14}$ However, there are important gaps in our knowledge about the influence of these factors. Firstly, most information has come from uncontrolled studies such as confidential enquiries (audits) ${ }^{5-8}$ or from small controlled studies with insufficient power to identify or quantify relative risks ${ }^{10}{ }^{12}{ }^{15}$; some have been open to interview bias ${ }^{12}{ }^{16}$ and some to age restriction. ${ }^{17}{ }^{18}$ Secondly, we know little about how to interpret associations with psychosocial factors and health behaviour in terms of cause and effect and hence whether addressing them will help to prevent asthma deaths. Our null hypothesis is therefore that the risk of asthma death in those with severe asthma is unrelated to psychological, social, and health behaviour factors.

This paper describes the results of a study designed to redress many of the problems inherent in previous studies of psychosocial and health behaviour factors and asthma death.
It is controlled to enable analysis of risk factors, uses a data collection method that reduces the risk of bias, is community based, includes cases up to the age of 65 to achieve a more representative group of deaths, and has a large sample size to provide good statistical power.

\section{METHODS}

A case-control approach was adopted in which "cases" were asthma deaths identified through the routine death certification system and controls with severe asthma were identified through the hospital information system. This method of identifying deaths was the only feasible way of obtaining a representative population sample, but it is not ideal because the death certificate, which is completed by the attending doctor, does not contain the clinical information to enable independent confirmation of the cause of death. The death certificate requires the certifying doctor to describe, in reverse order, the chain of conditions leading to death by recording in part I(a) of the certificate the immediate or proximal cause of death, in part $\mathrm{I}(\mathrm{b})$ the disease or condition leading to that recorded in part $\mathrm{l}(\mathrm{a})$, then part I(c) if a further condition led to part I(b). The condition recorded in the lowest position of part I is coded as the underlying cause of death and aggregated for routine statistical purposes. We included as cases not only those with asthma recorded as the underlying cause, but also those with asthma recorded elsewhere in part I providing the underlying cause was a lower respiratory condition. Essentially, we accepted the opinion of the certifying 
Table 1 Characteristics (\%) of cases and controls

\begin{tabular}{|c|c|c|c|c|}
\hline Patient characteristics & $\begin{array}{l}\text { Cases } \\
(n=533)\end{array}$ & $\begin{array}{l}\text { Controls } \\
(n=533)\end{array}$ & $\begin{array}{l}\text { Odds } \\
\text { ratio }\end{array}$ & $95 \% \mathrm{Cl}$ \\
\hline \multicolumn{5}{|c|}{ Age asthma first mentioned (years) $\ddagger^{* *}$} \\
\hline$<15 \S$ & 31.0 & 26.6 & 1.83 & $(1.10$ to 3.07$)$ \\
\hline $15-34$ & 21.4 & 22.1 & 1.38 & $(0.86$ to 2.21$)$ \\
\hline $35-44$ & 14.3 & 15.2 & 1.28 & $(0.78$ to 2.10$)$ \\
\hline $45-54$ & 16.5 & 18.6 & 1.15 & $(0.72$ to 1.84$)$ \\
\hline $55-64$ & 9.6 & 11.8 & 1.00 & - \\
\hline Missing & 7.3 & 5.6 & - & - \\
\hline Family history of asthma & 25.1 & 24.2 & 1.07 & (0.81 to 1.42$)$ \\
\hline Clinical evidence of atopy & 39.4 & 41.3 & 0.93 & $(0.72$ to 1.20$)$ \\
\hline Ever smoked & 58.3 & 59.3 & 0.94 & $(0.73$ to 1.21$)$ \\
\hline \multicolumn{5}{|l|}{ Co-morbidity mentioned ever } \\
\hline Major non-respiratory illness & 44.1 & 43.0 & 1.05 & $(0.81$ to 1.35$)$ \\
\hline COPD & 42.4 & 34.7 & $1.45^{* *}$ & (1.10 to 1.90$)$ \\
\hline Obesity & 30.6 & 25.0 & $1.37^{\star}$ & (1.04 to 1.81 ) \\
\hline \multicolumn{5}{|c|}{$\begin{array}{l}\text { *p<0.05, }{ }^{* *} p<0.01,{ }^{* * *}<<0.001 \text {. } \\
\text { †COPD defined as mention of chronic obstructive pulmonary disease, chronic obstructive airway disease, } \\
\text { chronic bronchitis, or emphysema. } \\
\text { FSignificance test for trend based on fitting age as a continuous variable. } \\
\S \text { Includes } 1.5 \% \text { with age of onset mentioned only as "in childhood"; these were assigned average value for } \\
\text { the }<15 \text { years category for purposes of significance testing. } \\
\text { Odds ratios (from conditional logistic regression) and p values calculated ignoring the missing and unknown } \\
\text { categories. Odds ratios are adjusted for sex. }\end{array}$} \\
\hline
\end{tabular}

doctor that asthma was in the chain or group of respiratory conditions responsible for the death. We did not include cases with asthma recorded in part II of the certificate. Necroscopic examinations were reported for $59 \%$ of deaths but these were not used to define an asthma death because their availability was variable, and we considered that the certifying doctor would have taken these results into account. Because we had access to the primary care records and hospital records (for hospital deaths), we were able to confirm that all the deaths had evidence of asthma in life.

The hypothesis related to the role of psychosocial factors in asthma death. Since deaths and probably psychosocial factors are related to severity, it was important to control for severity as a potential confounding factor. We had no way of selecting community controls with acute severe asthma to match deaths occurring over such a wide area, so we decided to use hospital admissions, matched for age, district, and date of death. The obvious problem with this approach is that some of these admissions would be matched with deaths occurring in the community. However, we decided not to exclude the community deaths as this would have undermined the community emphasis of the study. This factor would be taken into account in the analysis if appropriate. It is important to note that this study design does not enable us to investigate the relationship between psychosocial factors and the whole range of severity of asthma. This would have required the inclusion of milder cases sampled from the community.

The accuracy of a diagnosis of asthma as the cause of admission was examined by a validation study in which a panel of four respiratory physicians independently assessed a sample of 58 hospital records. They were asked to decide whether, on balance, the admission was caused by asthma. In 14 out of 58 admissions at least one physician could not reach a decision, all four in one instance. Excluding unsure responses, agreement between the physicians was moderate $(\mathrm{kappa}=0.6, \mathrm{p}<0.001)$. Of the 44 admissions where all four physicians reached a decision, they were all in agreement on $37(84 \%)$. In the three instances where three or four physicians did not agree with the discharge diagnosis and the patient was a study control, we examined the primary care records and there was clear evidence that the patient had been treated for asthma in the primary care setting.

\section{Cases}

The study period was 5 years from 1 January 1994 to 31 December 1998. The study areas were selected because they were also part of confidential enquiries into asthma deaths ${ }^{4-8}$ —England (East Anglia, North Essex, West Midlands, Northampton and Kettering, Cumbria and districts north of the Tyne), all of Wales, and the populated central belt of Scotland-and included $27 \%$ of the population of Great Britain. In Scotland data collection was restricted to the years 1996-1998 because of delays in ethical approval and the destruction of most records before 1996. Listings of all deaths where asthma (9th revision of the international classification of diseases (ICD 9) 493) was mentioned in part I of the death certificate were obtained from the Office for National Statistics and the General Register Office. Study entry criteria were: (a) age under 65 at time of death, (b) mention of asthma in part I of the death certificate, and (c) absence of a more credible and non-respiratory underlying cause of death such as cancer, ischaemic heart disease, or HIV infection.

\section{Controls}

For each case the hospital in which death occurred was identified or, if it was a community death, that to which he/she would probably have been admitted. We obtained from each hospital a complete list of asthma discharges (ICD 493) and this was used as a sampling frame to select one control per case, matched firstly for admission date $(58 \%$ within 1 month and $96 \%$ within 6 months of the date of death (the index date)) and then age (up to 5 years); $52 \%$ of controls were of our first selection, $27 \%$ of second, and $21 \%$ of third or higher; this was similar for each year of the study. The main reasons for rejection were either that scrutiny of the notes revealed that the patient did not have a primary diagnosis of acute asthma or that their general practitioner refused or failed to respond to the request for access to the primary care records. Controls who died in hospital at the index admission were excluded, but controls who died after the index admission and in the study period (fewer than 10) remained as controls.

\section{Ethical approval}

Ethical approval was obtained from the South Thames Multicentre Research Ethics Committee and Local Research Ethics Committees. Permissions were obtained from general practitioners to photocopy and take away masked records, health authorities to photocopy masked notes of cases, and hospitals to obtain lists of admissions and to photocopy the anonymised records required to validate the diagnosis of the asthma admission or the death (if the patient had been hospitalised). 
Table 2 Associations (\%) between asthma deaths, health behaviour, and psychosocial factors

\begin{tabular}{|c|c|c|c|c|c|c|c|c|}
\hline & \multicolumn{4}{|c|}{ Mentioned 5 years before index date } & \multicolumn{4}{|c|}{ Mentioned ever } \\
\hline & $\begin{array}{l}\text { Cases } \\
(n=533)\end{array}$ & $\begin{array}{l}\text { Controls } \\
(n=533)\end{array}$ & OR & $95 \% \mathrm{Cl}$ & $\begin{array}{l}\text { Cases } \\
(n=533)\end{array}$ & $\begin{array}{l}\text { Controls } \\
(n=533)\end{array}$ & OR & $95 \% \mathrm{Cl}$ \\
\hline \multicolumn{9}{|l|}{ Health behaviour: } \\
\hline Asthma drug non-compliance & 17.3 & 16.3 & 1.06 & (0.76 to 1.48$)$ & 22.0 & 19.1 & 1.19 & (0.87 to 1.62$)$ \\
\hline Poor inhaler technique & 15.2 & 13.7 & 1.14 & $(0.81$ to 1.59$)$ & 22.1 & 17.6 & $1.35^{*}$ & (1.00 to 1.83 ) \\
\hline Repeated non-attendance & 11.8 & 8.3 & 1.49 & (0.99 to 2.23$)$ & 15.8 & 11.3 & $1.47^{*}$ & (1.03 to 2.09 ) \\
\hline \multicolumn{9}{|l|}{ Psychological factors: } \\
\hline Anxiety & 25.5 & 30.0 & 0.82 & (0.62 to 1.07$)$ & 35.8 & 43.0 & $0.76^{*}$ & $(0.59$ to 0.97$)$ \\
\hline Sleepless & 39.4 & 41.7 & 0.92 & $(0.71$ to 1.17$)$ & 49.3 & 51.6 & 0.92 & $(0.72$ to 1.18$)$ \\
\hline Mention of sedatives $(n=532)$ & 21.8 & 22.7 & 0.96 & $(0.71$ to 1.30$)$ & - & - & - & - \\
\hline Depression & 28.7 & 28.7 & 1.03 & $(0.78$ to 1.36$)$ & 45.8 & 50.1 & 0.86 & (0.66 to 1.12$)$ \\
\hline Mention of antidepressants ( $n=532)$ & 23.5 & 27.4 & 0.83 & $(0.62$ to 1.11$)$ & 31.8 & 40.2 & $0.68^{* *}$ & (0.52 to 0.89$)$ \\
\hline Psychosis & 3.9 & 1.7 & $2.32 *$ & $(1.06$ to 5.06$)$ & 6.9 & 3.8 & $1.86^{*}$ & (1.08 to 3.21$)$ \\
\hline Mention of antipsychotics ( $n=532$ ) & 7.0 & 3.8 & $1.88^{*}$ & (1.08 to 3.29$)$ & - & - & - & - \\
\hline Overdose/self-harm & 4.1 & 5.3 & 0.78 & $(0.43$ to 1.39$)$ & 13.5 & 14.4 & 0.94 & (0.66 to 1.33$)$ \\
\hline Psychiatrist/psychologist/CPN referral $(n=532)$ & 16.5 & 16.5 & 1.00 & $(0.72$ to 1.40$)$ & 28.8 & 25.9 & 1.16 & (0.88 to 1.53$)$ \\
\hline Psychiatric inpatient or day patient $(n=532)$ & 3.6 & 5.5 & 0.64 & $(0.35$ to 1.15$)$ & 12.0 & 11.3 & 1.07 & (0.73 to 1.59 ) \\
\hline Mention of learning difficulties $(n=532)$ & 4.1 & 1.3 & $3.07^{*}$ & $(1.31$ to 7.20$)$ & - & - & - & - \\
\hline \multicolumn{9}{|l|}{ Social factors: } \\
\hline Sexual problems & 1.9 & 3.6 & 0.50 & (0.23 to 1.12$)$ & 3.6 & 7.1 & $0.45^{* *}$ & (0.24 to 0.82 ) \\
\hline Bereavement & 11.3 & 11.8 & 0.97 & (0.67 to 1.42$)$ & 25.0 & 28.0 & 0.88 & $(0.66$ to 1.16$)$ \\
\hline Separated/divorced & 3.9 & 3.4 & 1.16 & $(0.62$ to 2.18$)$ & 16.3 & 19.5 & 0.81 & (0.58 to 1.11$)$ \\
\hline Family problems & 17.5 & 16.1 & 1.13 & $(0.81$ to 1.59$)$ & 29.3 & 33.2 & 0.83 & (0.63 to 1.10 ) \\
\hline Domestic abuse & 2.6 & 2.6 & 1.06 & $(0.49$ to 2.31$)$ & 9.4 & 11.4 & 0.80 & (0.52 to 1.22 ) \\
\hline Isolation & 3.8 & 3.2 & 1.19 & $(0.60$ to 2.35$)$ & 6.0 & 5.3 & 1.15 & (0.67 to 1.96$)$ \\
\hline Housing problems & 14.3 & 12.0 & 1.24 & (0.87 to 1.78$)$ & 20.1 & 19.3 & 1.07 & (0.79 to 1.47$)$ \\
\hline Financial problems & 20.6 & 16.2 & 1.36 & (0.99 to 1.87 ) & 25.0 & 19.1 & $1.43^{*}$ & (1.06 to 1.94 ) \\
\hline Employment problems & 17.5 & 13.3 & 1.42 & (0.99 to 2.03$)$ & 28.1 & 20.1 & $1.60 * *$ & (1.19 to 2.17 ) \\
\hline Alcohol abuse & 14.5 & 9.9 & 1.51 * & (1.02 to 2.22 ) & 22.1 & 15.9 & $1.49^{*}$ & (1.08 to 2.07 ) \\
\hline Drug abuse & 6.6 & 3.6 & $1.84^{*}$ & (1.04 to 3.27 ) & 8.4 & 5.1 & $1.71^{*}$ & (1.03 to 2.83 ) \\
\hline Criminal record & 1.5 & 0.6 & 2.58 & (0.68 to 9.73 ) & 4.9 & 4.1 & 1.17 & (0.64 to 2.12 ) \\
\hline
\end{tabular}

\section{Data extraction and coding}

For the 5 years before the index date, data were extracted in the academic department blind to case-control status from photocopied and anonymised primary care records. For the period before this, data were extracted non-blind on site with a 5\% sample of complete notes being copied for blind validation. "Ever mention" of a variable refers to both periods combined. Selected clinical variables and psychosocial and health behaviour factors based on those recorded in confidential enquiries $^{3-8}$ are listed in tables 1 and 2, respectively. Psychosocial factors could be either: (1) characteristics of the individual that, while not having a negative connotation in themselves, could be relevant to the impact or management of asthma (for example, learning difficulties) or (2) factors that would normally be considered to be adverse (for example, drug abuse, mental illness). Health behaviour factors were those that related to adherence to asthma management and markers included non-attendance for appointments in practices and hospital or self-discharge, poor compliance with asthma medication, and inadequate inhaler technique.

Variables were mainly binary in nature (yes/no) based on their presence or absence in the notes. Explicit mention of a factor was coded as "yes". No mention of a factor was coded as "no", although this could mean either that it was recorded as not present or that the data were missing. The extracted data were then coded and double entered using the public domain software package Epi Info 6.04.

\section{Statistical methods}

The data were analysed as for a matched case-control study using cross tabulations and conditional logistic regression analysis which led to the calculation of odds ratios and 95\% confidence intervals. Conditional logistic regression modelling was used to investigate statistical interactions and independ- ent effects, with statistical significance tests based on differences in log likelihood. Where it became necessary to enter a pair of highly correlated explanatory variables into the same model-for example, "alcohol abuse" and "drug abuse" - a composite variable such as "alcohol or drug abuse" was constructed to avoid problems with multi-colinearity. Analyses were conducted using STATA software. ${ }^{19}$

\section{RESULTS}

\section{Identification of cases}

Six hundred and eighty one cases of asthma death met the study entry criteria; 148 (22\%) were subsequently excluded. Reasons for exclusion were incomplete or missing records $(\mathrm{n}=81,12 \%)$, miscoded clinical diagnosis $(\mathrm{n}=33,5 \%)$, refusal or non-response from general practitioners $(n=10,1 \%)$, cases abandoned because of time constraints $(n=18,3 \%)$, and cases not resident in the study area $(n=6,1 \%)$. Of the remaining 533 deaths, 279 (52\%) died in the community, 237 $(45 \%)$ died in hospital ( 54 on the first day), and $17(3 \%)$ were dead on arrival. One hundred and seventy (57\%) of the 296 who died outside hospital had no previous admissions for asthma (according to primary care records and hospital systems) compared with 90 (38\%) of the 237 of those who died in hospital. Necroscopic examinations were carried out on $115(49 \%)$ hospital deaths and $202(68 \%)$ community deaths.

On the death certificates asthma was recorded in the lowest position of part I as the underlying cause in 499 (94\%) of 533 cases. Of the remainder $(\mathrm{n}=34), 12(2 \%)$ comprised chronic obstructive airways disease (COAD), chronic bronchitis, emphysema, bronchiectasis, or pneumonia. There were 22 cases $(4 \%)$ where the underlying cause was coded as non-respiratory but scrutiny of records and necroscopic 
reports indicated that they were miscoded respiratory deaths and eligible for inclusion. In 70 cases (13\%) other chronic lung diseases were recorded in part I, but not as the underlying cause (COAD in $47(9 \%)$, chronic bronchitis in $10(2 \%)$, emphysema in $10(2 \%)$, and bronchiectasis in three $(1 \%))$; pneumonia was mentioned in $46(9 \%)$. In all, 77 (14\%) had mention of COPD in part I of the death certificate but less than $2 \%$ had COPD as the final underlying cause.

\section{Demographic and clinical characteristics}

The median (interquartile range) age was 53 years (40-59) for cases and 53 years (40-58) for controls. $4 \%$ of cases were aged under 15 years and $18 \%$ under 35 years. $60 \%$ of cases and $63 \%$ of controls were female. Occupation was mentioned for 91 cases and 120 controls. Of these, similar proportions were housewives (11\%) and manual workers (cases 46\%, controls $48 \%$ ). The patterns of asthma related hospital admissions were similar for cases and controls with $35 \%$ of each group having had an admission in the year before the index date. $22 \%$ of cases and $20 \%$ of controls had had more than two admissions during the previous 5 years, and the mean number of inpatient days among those admitted was 36 and 30, respectively.

Cases had on average an earlier onset of asthma (table 1). A family history of asthma and clinical evidence of atopy (mention of eczema or hay fever) were similar for cases and controls. Approximately $60 \%$ of cases and controls had a history of smoking, with one fifth recorded in the previous year. There were no significant differences between cases and controls for co-morbidity with major non-respiratory diseases. The risk of asthma death was positively associated with recorded COPD (emphysema, chronic bronchitis or COAD; odds ratio (OR) 1.45, 95\% confidence interval (CI) 1.10 to 1.90 ) and mention of obesity (OR $1.37,95 \%$ CI 1.04 to 1.81 ).

\section{Health behaviour: adherence to asthma management} Mention ever of poor inhaler technique and repeated non-attendance for practice/hospital asthma appointments (including self-discharge) were both associated with an increased risk of asthma death (OR 1.35, 95\% CI 1.00 to 1.83 ; OR $1.47,95 \%$ CI 1.03 to 2.09 , respectively; table 2 ). There was no evidence of an association with non-compliance with taking asthma drugs.

\section{Psychological factors}

There was little overall difference in recorded psychological factors (75\% of cases and $79 \%$ of controls), but when the factors were examined individually a mixed picture emerged (table 2). Any mention of psychosis was associated with a near doubling in the risk of asthma death (OR 1.86, 95\% CI 1.08 to 3.21 ), a finding corroborated by the prescription of antipsychotic drugs (OR 1.88, 95\% CI 1.08 to 3.29 ) in the previous
5 years. Learning difficulties were mentioned infrequently in the previous 5 years, but were nevertheless associated with a threefold increase in risk (OR 3.07, 95\% CI 1.31 to 7.20). Mention ever of anxiety was associated with a reduction in risk (OR $0.76,95 \%$ CI 0.59 to 0.97 ). This inverse association with anxiety appeared to be confined to females (OR 0.69, 95\% CI 0.50 to 0.96 ) rather than males (OR $0.98,95 \%$ CI 0.64 to 1.50 ), but the interaction was not statistically significant $(p=0.13)$. There was no evidence of an association with mention of depression but the cases were significantly less likely to have been treated at some time with antidepressants (OR 0.68, 95\% CI 0.52 to 0.89 ). There was no significant association with prescription of sedatives in the previous 5 years, mention of sleeplessness, overdose, or other self-harm or referral for psychiatric treatment. All of the psychological factors with significant associations for any mention ever showed odds ratios of similar size and direction when only data extracted blind for the previous 5 years were analysed.

\section{Social factors}

Overall, mention of social factors was equally common in cases $(67 \%)$ and controls (67\%) but, as with psychological factors, there was a mixed picture when the factors were examined individually (table 2 ). Increased risk of asthma death was associated with a mention ever of financial (OR $1.43,95 \%$ CI 1.06 to 1.94 ) and employment problems (OR $1.60,95 \%$ CI 1.19 to 2.17 ). Alcohol and drug abuse (mentioned ever) were both associated with increased risk of asthma death (OR $1.49,95 \% 1.08$ to 2.07 and OR $1.71,95 \%$ CI 1.03 to 2.83 , respectively). With the exception of reported alcohol abuse, these associations with social factors were stronger in males than in females, although tests for statistical interactions with sex were all non-significant at the 5\% level. A report at some time of sexual problems was associated with a $55 \%$ lower risk of asthma death (OR $0.45,95 \%$ CI 0.24 to 0.82 ). There was no significant association with mention of bereavement, separation, family problems, domestic abuse, isolation, or housing problems. When analysis was restricted to data from the last 5 years, the previously significant odds ratios were similar in size and direction.

\section{Multifactorial analysis}

Some of the factors that were statistically significant in table 2 were so highly interrelated that their associations with asthma death could not be disentangled using conditional logistic regression-for example, financial problems, employment problems. We therefore created composite variables such as "financial or employment problems". Following mutual adjustment, odds ratios for the psychosocial factors and health behaviour factors shown in table 3 changed little and remained statistically significant, except for alcohol/drug abuse which lost significance when adjusted for psychosis (OR

Table 3 Associations between asthma death and significant health behaviour and psychosocial factors $(n=1064)$

\begin{tabular}{|c|c|c|c|c|}
\hline & $\begin{array}{l}\text { Odds ratio }(95 \% \mathrm{Cl}) \\
\text { adjusted for sex }\end{array}$ & $\begin{array}{l}\text { Odds ratio }(95 \% \mathrm{Cl}) \\
\text { adjusted for sex and the } \\
\text { other psychosocial factors }\end{array}$ & $\begin{array}{l}\text { Odds ratio }(95 \% \mathrm{Cl}) \text { adjusted } \\
\text { for sex, the other psychosocial } \\
\text { factors and other factors* }\end{array}$ & $\begin{array}{l}\text { p value } \\
\text { from full } \\
\text { model }\end{array}$ \\
\hline Financial/employment problems mentioned ever & $1.44(1.10$ to 1.87$)$ & 1.55 (1.16 to 2.07$)$ & $1.45(1.07$ to 1.95$)$ & 0.01 \\
\hline Drug/alcohol abuse mentioned ever & $1.43(1.06$ to 1.92$)$ & $1.21 \quad(0.87$ to 1.68$)$ & $1.19(0.85$ to 1.66$)$ & 0.31 \\
\hline Anxiety/prescribed antidepressant mentioned ever & $0.63(0.48$ to 0.81$)$ & $0.52(0.39$ to 0.70$)$ & 0.52 (0.38 to 0.70$)$ & $<0.001$ \\
\hline Sexual problems mentioned ever & 0.45 (0.24 to 0.82$)$ & $0.49(0.26$ to 0.93$)$ & $0.46(0.24$ to 0.90$)$ & 0.02 \\
\hline $\begin{array}{l}\text { Psychosis mentioned ever/prescribed psychoses drugs } \\
\text { in previous } 5 \text { years }\end{array}$ & $1.69(1.08$ to 2.63$)$ & $1.89(1.15$ to 3.12$)$ & $2.06(1.23$ to 3.45$)$ & 0.005 \\
\hline Learning difficulties mentioned in previous 5 years & 3.07 (1.31 to 7.20$)$ & $2.79(1.16$ to 6.73$)$ & 2.62 (1.09 to 6.33$)$ & 0.02 \\
\hline $\begin{array}{l}\text { Repeated non-attendance/poor inhaler technique } \\
\text { mentioned ever }\end{array}$ & 1.55 (1.18 to 2.04$)$ & $1.47(1.10$ to 1.96$)$ & 1.49 (1.10 to 2.00$)$ & 0.008 \\
\hline
\end{tabular}

The above ORs (adjusted for other psychosocial factors) were obtained from a multiple conditional logistic regression including all of the above psychosocial factors.

*Other factors are COPD (defined as mention of COPD, COAD, chronic bronchitis or emphysema), obesity, and age of onset (including missing data). 
1.33, 95\% CI 0.98 to 1.80). Additional adjustment for age of asthma onset, COPD, and obesity made little difference (table 3 ). The odds ratio for alcohol/drug abuse without mutual adjustment but adjusted for sex, COPD, age of onset, and obesity was 1.40 (95\% CI 1.04 to 1.89). The associations listed in table 3 therefore all appear to be independent of certain markers of asthma severity (age of onset and COPD) and, with the exception of alcohol/drug abuse, also appear to be independent of one another.

\section{DISCUSSION}

Past controlled studies of psychosocial factors and health behaviour in severe or fatal asthma have been highly variable in terms of asthma severity ${ }^{1620}$ and the source of the study population, ${ }^{11} 151721$ thereby making comparisons across studies problematic. Design problems have included low power due to small numbers, ${ }^{1012}$ bias due to the absence of blinding the investigator to the status of the subjects, ${ }^{16}{ }^{17}$ the possibility of interviewer bias, ${ }^{12}{ }^{16}$ selection of the cases and controls by requiring hospital admission, ${ }^{11}{ }^{1521}$ and greater age restrictions. ${ }^{11}{ }^{18}$ There has been no consistency across studies in either the types of psychosocial or health behaviour factors studied nor with the way that apparently similar constructs are measured. ${ }^{316}$

Our study had the advantage of being large, community based, and of employing an unbiased method of ascertaining the history of psychosocial and adherence factors in the previous 5 years. However, this was at the expense of completeness since such data are not recorded in primary care records in a systematic fashion. An alternative would have been to use hospital records or to interview relatives and general practitioners, but the former would exclude deaths without prior admission and the latter would be biased by the informants' knowledge of the status of the subject. While there was a potential for bias in extraction of data beyond 5 years from the index date, this seems unlikely in view of the similarity of results for the two time periods of 5 years before (blind extraction) and ever (not blind for the earlier period).

Confidence in our results was strengthened by our cases and controls being well balanced in terms of age and sex. Contrary to the findings of another study, the level of recent asthma admission was also similar. ${ }^{22}$ Clinically, cases and controls were similar in terms of atopic diseases, family history of asthma, and smoking. However, there were indications that the cases were more severe because they had an earlier onset of their condition and more COPD. Controlling for the age at onset or presence of COPD as markers of severity made little difference to the magnitude of the associations with psychosocial factors in the model (table 3 ).

Some of the positively associated health behaviour and psychosocial risk factors identified (repeated non-attendance or poor inhaler technique, psychosis or antipsychotic drug treatment, drug or alcohol abuse, financial or employment problems) support the conclusions of earlier controlled and uncontrolled studies. ${ }^{3-8}{ }^{10}{ }^{16}$ Contrary to other studies, the positive association with antipsychotic drug treatment was not accompanied by any evidence of a similar association with sedative treatment. ${ }^{23}{ }^{24}$ The association with learning difficulties corresponds to evidence that this is a major risk factor for deaths from respiratory diseases. ${ }^{25}$ However, it is notable that risk of asthma death was not significantly related to some psychosocial factors previously highlighted (domestic abuse, family problems, bereavement and social isolation). ${ }^{3-8}{ }^{10}$ Moreover, some psychosocial factors (anxiety and prescription of antidepressants) were associated with a reduced risk of death. Given a possible association between anxiety and hospital admission, it is possible that our controls consisted of a less severe and more anxious group than our cases by design. When our analysis was restricted to cases dying in hospital and their matched controls, the inverse association with anxiety persisted (data not shown). This is in contrast to the findings of Kolbe et $\mathrm{al}^{26}$ who found no evidence of a difference in anxiety between those admitted to intensive care with severe life threatening asthma and those admitted to general wards with asthma. While we acknowledge that our controls may be more anxious and less severe, our conditional logistic regression model by including the term anxiety/prescribed antidepressants should help to adjust for any bias.

The psychosocial factors and health behaviour considered here are very heterogeneous in their nature and causes. The interactions between them are complex, as are the various mechanisms by which they might influence the outcome of asthma or be influenced by severe asthma. Nevertheless, we propose two potential pathways to explain our observations. The first is that severe asthma may give rise to psychosocial or health behaviour problems which, in turn, reduce the quality of care by various means, thus setting into motion a vicious spiral of increasing severity interacting with psychosocial adversity that may lead to death. The second mechanism is one in which there is competition between asthma and the psychosocial factor for available support with the former being accorded a relatively low priority when compared with the other stressors in the patients' life. Our finding that treatment with antidepressant drugs is associated with a lower risk of death tends to support both hypotheses. However, these ideas are not supported by our observation that associations of psychosocial factors with risk of asthma death are largely independent of markers of adherence and service usepractice contacts and systemic steroid prescription (preliminary unpublished observations).

Because there are no equivalent prevalence data available for the general population, it is difficult to evaluate our impression that there were high levels of psychosocial factors in both cases and controls. Nonetheless, controlled and uncontrolled studies of asthma deaths and near fatal attacks have also reported seemingly high levels of psychosocial factors. ${ }^{3-8} 162021$

We have confirmed in a controlled study the importance of certain psychosocial and adherence to management factors in premature deaths from asthma compared with hospital admissions. Some factors were related to a reduction in risk of death but, for many factors, there was little evidence of any association. Our study also provides indirect evidence that a high level of psychosocial factors is a feature of severe asthma generally; this has important implications for the appropriate care of severe asthma and further research is required in this area across a greater range of asthma severity.

\section{ACKNOWLEDGEMENTS}

We are grateful for the advice and support of our steering committee, the Mortality and Severe Morbidity Working Group of the National Asthma Task Force, which included: J Ayres (Chairman), B Harrison (past Chairman), D Stableforth, M Burr, W Berrill, V Fox, T Williams, S Wright, C Bucknall, F Chung, C Godley, G Houghton, T MacKay, S McKenzie, G Mohan, J Poundsford and A Ross. We also thank R Beasley, J Crane and N Pearce of the Wellington Asthma Research Group, who are involved with another part of this study, for their advice; research assistants B Khoshaba, B Davies, B Eldridge, S MacArthur and $M$ Wardroper for their diligent fieldwork and the medical students who assisted with data extraction; and the large number of general practices, health authority personnel and hospital staff who assisted us. The Office for National Statistics and the General Register Office supplied copies of death certificates.

\footnotetext{
Authors' affiliations

P M Sturdy, C R Victor, H R Anderson, J M Bland, B K Butland, C Peckitt, J C Taylor, Department of Public Health Sciences, St George's Hospital Medical School, London SW 17 ORE, UK

B D W Harrison, Department of Respiratory Medicine, Norfolk and Norwich University Hospital NHS Trust, Norwich NR 1 3SE, UK
} 
The study was funded jointly between the National Research and Development Asthma Management Programme (contract number AM1 /05/002) and the National Asthma Campaign through a grant from Glaxo Wellcome (now GlaxoSmithKline).

\section{REFERENCES}

1 Department of Health. Asthma: an epidemiological overview. London: Department of Health, 2000.

2 Lung and Asthma Information Agency, 2000

3 Wareham NJ, Harrison BD, Jenkins PF, et al. A district confidential enquiry into deaths due to asthma. Thorax 1993;48: $1117-20$

4 Mohan G, Harrison BD, Badminton RM, et al. A confidential enquiry into deaths caused by asthma in an English health region: implications for general practice. Br J Gen Pract 1996;46:529-532.

5 Burr ML, Davies BH, Hoare A, et al. A confidential inquiry into asthma deaths in Wales. Thorax 1999;54:985-9.

6 Bucknall CE, Slack R, Godley CC, et al. Scottish Confidential Inquiry into Asthma Deaths (SCIAD), 1994-6. Thorax 1999;54:978-84.

7 Jones K, Berrill WT, Bromly CL, et al. A confidential enquiry into certified asthma deaths in the North of England, 1994-96: influence of co-morbidity and diagnostic inaccuracy. Respir Med 1999;93:923-7.

8 Harrison BD, Slack R, Berrill WT, et al. Results of a national confidential enquiry into asthma deaths. Asthma J 2000;5:180-6.

9 British Thoracic Association. Death from asthma in two regions of England. BM 1982;285:1251-5.

10 Rea HH, Scragg R, Jackson R, et al. A case-control study of deaths from asthma. Thorax 1986;41:833-9.

11 Grainger J, Woodman K, Pearce N, et al. Prescribed fenoterol and death from asthma in New Zealand, 1981-7: a further case-control study. Thorax 1991;46:105-11.

12 Jalaludin BB, Smith MA, Chey T, et al. Risk factors for asthma deaths: a population-based, case-control study. Aust NZ J Publ Health 1999;23:595-600

13 Innes NJ, Reid A, Halstead J, et al. Psychosocial risk factors in near-fatal asthma and in asthma deaths. J R Coll Physicians Lond 1998;32:430-4.
14 Harrison BDW. Psychosocial aspects of asthma in adults. Thorax 1998;53:519-25.

15 Guite HF, Dundas R, Burney PG. Risk factors for death from asthma, chronic obstructive pulmonary disease, and cardiovascular disease after a hospital admission for asthma. Thorax 1999;54:301-7.

16 Campbell DA, McLennan G, Coates JR, et al. A comparison of asthma deaths and near-fatal asthma attacks in South Australia. Eur Respir J 1994;7:490-7.

17 Crane J, Pearce N, Flatt A, et al. Prescribed fenoterol and death from asthma in New Zealand, 1981-83: case-control study. Lancet $1989 ; 1: 917-22$

18 Spitzer WO, Suissa S, Ernst $P$, et al. The use of beta-agonists and the risk of death and near death from asthma. N Engl J Med 1992;326:501-6.

19 Stata Corp. Stata statistical software. Release 5.0. College Station, TX, Stata Corporation, 1997.

20 Kolbe J, Fergusson W, Vamos M, et al. Case-control study of severe life threatening asthma (SLTA) in adults: demographics, health care, and management of the acute attack. Thorax 2000;55:1007-15.

21 Sudo $M$, Kobayashi $H$, Nakagawa T, et al. A comparison of asthma deaths and near-fatal asthma attacks (in Japanese). Arerugi - Jpn J Allergol 1996;45:1262-9.

22 Crane J, Pearce N, Burgess C, et al. Markers of asthma death or readmission in the 12 months following a hospital admission for asthma. Int J Epidemiol 1992;21:737-44

23 Joseph KS. Asthma mortality and antipsychotic or sedative use. What is the link? Drug Safety 1997:16:351-4.

24 Joseph KS, Blais L, Suissa S. Increased morbidity and mortality related to asthma among asthmatic patients who use major tranquillisers. BM 1996;312:79-82.

25 Hollins S, Attard MT, von Fraunhofer N, et al. Mortality in people with learning disability: risks, causes, and death certification findings in London. Dev Med Child Neurol 1998;40:50-6.

26 Kolbe J, Fergusson W, Vamos M, et al. Case-control study of severe life threatening asthma (SLTA) in adults: psychological factors. Thorax 2002; 57:317-22. 